\title{
South east Peru II: delivery of primary medical care by hovercraft along the Apurimac river
}

\author{
L. ARROW，W M GOULD，D C LANGLEY， H F PILE，A M PROSSER，C E S C WHITE，D N WOOD
}

During the latter part of 1982 a joint services expedition travelled to Peru. The aims of this expedition included the setting up of the world's first hover doctor service on one of the main tributaries of the Amazon river to provide a primary medical care service for Campa and Quechua Indians living in villages close to the river. We describe the project, the problems encountered, and the prospects for the future.

\section{Background}

The Joint Services Expedition Trust was formed in 1960 to encourage major expeditions. Towards the end of 1978 Squadron Leader Michael Cole took a joint services team of 26 men to the Himalayan Kingdom of Nepal to conduct a three month feasibility study. He used a small hovercraft on one of Nepal's major rivers to find out whether this craft was suitable to deliver primary medical care to people living along this violent river. Many lessons were learnt from that expedition, and the hovercraft was modified, but it was decided that a primary health care system using the hovercraft on that particular stretch of river was not practical at that time. That, however, was not the end of the story.

Julian Latham, a former Rhodesian farmer, had been working in the Amazon basin of Peru for some years among the Quechua and Campa Indians, who live in village settlements close to the Apurimac river, and he had helped the people to establish a cooperative for the sale and marketing of their cash crops. Their health was poor, and a simple base hospital was built, but as the distances up or down river might mean a journey of more than 100 miles for some villagers, he realised that primary medical care must be more readily available. Canoe travel by river was both expensive and dangerous. Michael Cole's work in Nepal came to Julian Latham's attention, and another joint services expedition was conceived.

\section{The medical team}

Michael Cole gathered together a team of people who could help him achieve the aims he had laid down for the expedition. Applications were invited from doctors in the armed services, from dentists, engineers, pilots, administrators, etc, and the team was chosen from hundreds of applicants. Four general practitioners from a group practice in Devon had been invited to provide medical care as civilian members of the expedition.

Bristol Maternity Hospital, Bristol, Avon

L ARROW, SRN, pupil midwife

Brixham, $S$ Devon

W M GOULD, FRCS, DTM\&H, general practitioner

D C LANGLEY, MB, MRCGP, general practitioner

$\mathrm{H}$ F PILE, MB, BS, general practitioner

D N WOOD, MB, MRCGP, general practitioner

Royal Naval Hospital, Haslar, Gosport, Hants

A M PROSSER, BDS, dental surgeon

Royal Naval Hospital, Plymouth, Devon

C E S C WHITE, BDS, BSC, assistant in oral surgery

Correspondence and requests for reprints to: Dr W M Gould, St Luke's House, New Road, Brixham, Devon TQ5 8NA.
One of us (WMG) had previously worked in Nepal for almost 13 years and had taken part in the preliminary planning of the Nepal hovercraft expedition (see fourney to the Fourth World, by Michael Cole). The medical team was strengthened by the addition of two naval dentists and a civilian nurse.

\section{Aims and objectives}

The aims and objectives of the expedition were firstly, the delivery of hovercraft to two groups-the Amazon Trust, whose leader is Julian Latham, and the Regions Beyond Missionary Union, a missionary group working 600 miles down river, secondly, the training of Peruvian nationals to pilot and service the hovercraft, thirdly, the establishment of a network of clinics, giving primary health care along a 100 mile stretch of river and a regular weekly visit by the doctor to each of these clinics, fourthly, the linking of clinics and hovercraft by radio to a base, and lastly the provision of clean water supplies to selected villages.

This paper is primarily concerned with the third of these aims and objectives.

\section{The medical team and their responsibilities}

The four general practitioners from Devon boxed and coxed so that most of the time there were two of us in Devon and two on the Amazon, and with the help of a locum tenens, we managed to continue to run a busy general practice and at the same time to plan and run the hover doctor service on the Amazon.

Medical cover for the expedition team, together with supervision of facilities at base camp, such as messing, provision of drinking water, latrines, etc, were additional responsibilities. We were helped to a great extent by our two naval dentists and by our civilian nurse. Once we were on the river and into the programme, a Quechua-speaking Peruvian nurse, who also acted as interpreter, gave us invaluable help and support. Three of the engineering team could speak Spanish, and always one of them accompanied us on our river trips and acted as interpreter in the clinics. Without their help we would have found our medical work very difficult indeed.

\section{Health workers}

Sanitarios (medical workers) had been appointed in five of the villages we visited regularly. These young men and women follow a nine month course in basic health care run by the Peruvian government before they take on the responsibility of running a village clinic, and provided that they are adequately supervised, encouraged, and have communication with someone senior, the scheme works well. We believe our greatest contribution during three months was to have left behind people who had gained in their medical knowledge and improved on their basic medical skills. Therefore, one of our prime objectives was to use each clinic visit as a teaching opportunity both for our own Peruvian nurse in the team and for the sanitarios. As relationships developed, the weekly visit became a means of encouragement to the sanitarios, who then began to select problem cases for us to see and discuss with them. The culmination of our teaching efforts was a two day seminar held just before we left which was attended by all the sanitarios. The programme covered the source, storage, sterilisation, and uses of water, the 
importance of a balanced diet, care of teeth, and the cooking, covering, conserving, and cleanliness of food. The types of parasites, their effect on health, the cure by medicine, and prevention were discussed. In the afternoon there were practical demonstrations of healthy living, first aid, and a discussion on the use of statistics. The second day of the programme dealt with mothers and children and showed a health chart, and a vaccination programme. There were talks and demonstrations on sterilising and suturing, on infection in wounds and treatment with penicillin. This was followed by a practical demonstration on the technique of injection, and indications for injection. Later on the second day the top 20 medicines were listed and the equipment and supplies for a health centre were discussed. The importance of keeping records, both financial and statistical, was emphasised. Teachers from 40 different village schools also attended part of the seminar and each teacher was presented with a basic first aid box to take back to their village school.

\section{Preparation and strategy}

The whole subject of preparing for the expedition from a medical standpoint is covered in another paper ( $p 373$ ). The delivery of health care to a place such as the Apurimac valley needed careful thought. Because of several years of previous experience in Asia, one of us (WMG) was able to suggest priorities and goals, and hours were spent in discussion and reading, in particular three books: Where there is no Doctor by Werner, Medical care in developing countries by Maurice King, and Paediatric priorities in the developing world by $\mathrm{D}$ Morley. These proved invaluable in our orientation to Third World medicine. We determined to concentrate maximum effort on the children under 5 and their mothers, realising that these were the groups at greatest risk. We were conscious that the medical service we were to establish would not be second rate Western style medicine but medicine appropriate for the Third World. We designed three different forms to help us in standardising our work in gathering statistics and in building up a picture of the disease pattern. The first form to be used on our first visit to a village provided information about the facilities in any village-for example, the population, the school, the water supply, etc. It also recorded the answer to a very important question-namely, what do the villagers themselves think is the biggest need in the village? The second form was used to document the information gathered on the children aged from 0 to 5 years. Every child was weighed and measured and, using a Nabarro height for weight chart, together with the measurement of upper arm circumference (ages 1-5 only), was assessed for signs of malnutrition. The position of the child in the family and the deaths of any brothers and sisters were also recorded. The third form was a disease pattern chart which enabled us to record each patient's diagnosis and thus obtain a general picture of the commonest diseases.

\section{Location and situation}

The expedition established base camp opposite San Francisco, a frontier town on the upper reaches of the Amazon river in the Andean foothills of Peru. It was a shanty town with a population of over 14000 folk living in very poor housing conditions and without a single latrine in the whole town. The local hospital, which had obviously seen better days, was staffed by one Peruvian doctor and a Peruvian dentist. Both Quechua and Campa Indians were treated there, prices were high, and often treatment was started but was stopped because the patient's family ran out of funds. We established a self sufficient unit, supplementing our forces compo rations with local fruit and vegetables. Water supplies were always heavily contaminated but a portable water filtration plant dealt with this problem, and during the whole of the expedition we had no outbreak of gastroenteritis. In the town itself, but on the edge of the river, a large building had been erected to house the hovercraft (four in number) as well as to provide a service centre for the craft. In this building one room was allocated to the medical team and we were able to unpack the supplies of drugs and equipment which we had shipped out. Some of these medicines and supplies had come directly from armed forces stocks, but many of the major pharmaceutical companies had made donations and we were fortunate in starting our programme with well stocked shelves. At the end of each village trip our medical bag would be restocked from these supplies. Ultimately our aim was to simplify the medicines available rather than to reproduce $M I M S$, and we developed the concept of relying on "the top twenty": analgesic, either aspirin or paracetamol tablets; penicillin, by injection, tablets or syrup; metronidazole tablets; oxytetracycline tablets; chloramphenicol; piperazine phosphate syrup; mebendazole tablets; cough mixture; multivitamin tablets; iron tablets; chloroquine tablets; antacid tablets or liquid; chlorpheniramine tablets; benzyl benzoate liquid; steroid skin cream; antiseptic skin cream; antifungal cream; eye ointment; vaginal cream and pessaries; combination of isoniazid and thiacetazone; INH combination for tuberculosis. In addition there were dressings, tape, suture kit, chlorhexidine, gloves, $\mathrm{KY}$ jelly, and syringes, needles, and sterets.

\section{Clinic programme and our patients}

Each week we visited 11 clinics along a 100 mile stretch of river spending three days up river and two days down river. We spent the sixth day attending a clinic in the jungle, less than two hours walk from base camp. Nine of the clinics were in Quechua villages and most of these already had a purpose built medical centre, but the Campa villagers had to make use of one of their bamboo huts.

There were dramatic differences in the two ethnic groups. The Quechuas, direct descendants of the Incas, are a colourful, outgoing people, taken up with small scale farming or trading. The Campas live in the depths of the jungle in a tight tribal system with a chief, who is very powerful; they hunt in the jungle to eat; men, women, and children all wear a long brown cotton gown hanging loosely from the shoulders. In the first few weeks, while the hovercraft were prepared for use, we used the local canoes for our clinic visits. When the hovercraft became available we found them faster, safer, drier, and more economical. But while a canoe could take a full medical team with almost unlimited supplies, the hovercraft was restricted to four people and limited supplies. The people would gather in anticipation of the clinic opening in the Quechua villages, and the starting time would be our responsibility. In the Campa villages, however, we could only begin to see patients when the chief had agreed. Children under 5 and mothers were given priority. Each child was weighed, height measured, and arm circumference checked. The child's upper arm circumference is almost the same between the ages of 1 and 5 years, so if we measure the middle of the upper arm in this age group we can find the malnourished children. Similarly, using the Nabarro weight for height chart, an index of malnourishment is provided and the children at risk can be spotted. A simple road to health card which the mother kept in a polythene envelope (patient retained record) was brought to the clinic at each visit. A large number of the children had worms - ascaris, threadworm, or hookworm-and it became almost routine to offer treatment for the parasites even if the mother never mentioned the problem.

\section{Findings}

In the under 5 age group we recorded parasitic infection in $32 \%$, respiratory infections in $30 \%$, gastroenteritis in $20 \%$, skin infections in $15 \%$, and severe malnutrition in $8 \%$. One helpful item in teaching the mothers about the need for fluid replacement in gastroenteritis was a simple plastic spoon with a large measure at one end for sugar and a small measure at the other 
end for salt. Instructing the mother to make up a drink using a cup full of boiled water with a measure of both sugar and salt mixed in, made the matter of fluid treatment relatively simple. When our supplies of plastic spoons ran out we recommended mothers to put into a cup of boiled water enough sugar to fill the cupped palm of the hand and as much salt as could be held in the tip of the thumb nail.

Our policy of concentrating on the children under 5 was justified retrospectively when a random sample of 100 children from the 11 clinics visited indicated an overall $42 \%$ mortality in this group. The figure is even more staggering when we compare it with a $1 \%$ figure in Britain. In children under 5 the first few days and weeks are crucial, and our observations suggest that the three commonest causes of death in these early days and weeks were (a) neonatal tetanus and septicaemia because of inadequate and dirty techniques during delivery, $(b)$ malnutrition as mother's milk dried up, and (c) respiratory infections progressing to fatal pneumonia.

There was evidence of malnutrition in $40 \%$ and severe malnutrition in $8 \%$ of these young children, and those particularly at risk were between 1 and 3 years, as another child was born into the family and they were weaned off the breast.

In the group from 5 to 15 years of age parasitic infections were very common $(48.5 \%)$, and among those with respiratory infections $(13.5 \%)$, there was a high proportion with pulmonary tuberculosis. Many children had skin infections, gastroenteritis $(7 \cdot 5 \%)$, and dysentery.

The disease pattern in the adult population showed little variation between the sexes, though there was more anaemia in women, because of frequent pregnancies, little if any planned antenatal care, gynaecological abnormalities, as well as the inevitable hookworm anaemia.

Both men and women had a high incidence of symptoms of peptic ulcer, higher in the men because of their drinking habits and possibly because they chewed coca. Low back pain, as in the West, was a frequent complaint of both sexes. Often we heard about people with yellow fever and hepatitis, but we saw very few in the clinics. One village, some four hours walk away from one of our up river clinics, had a very high incidence of pulmonary tuberculosis but we were unable to visit them and could only send medicine. The combination of isoniazid $300 \mathrm{mg}$ with thiacetazone $150 \mathrm{mg}$ is a once daily tablet and relatively cheap. We heard of, but never saw, some people who had rabies and others who had been bitten by snakes.

Our dentists had planned to combine their dentistry with helping in the medical programme, but they found themselves more than fully occupied with tooth extractions (680), teaching preventive dental health, and instructing some of the sanitarios in extraction techniques. The future of the service initiated by us depends on the people; on the Peruvian doctors who will take on the responsibility of running an efficient, reliable, and caring service; on the Peruvian nurses who will work alongside the doctors; and on the sanitarios who work in the village clinics every single day but see the doctor and the nurse only for a few hours each week; on the Peruvian pilots who guide the craft through difficult rapids on a river which is continuously changing and at all times is challenging; on the Peruvian engineers who have been trained to maintain and service the hovercraft; and on others who have the responsibilities of ordering supplies and carrying out day to day administration. We have proved that it can be done. In so doing we have not met all the medical needs of all the people of Peru, but we have shown that given the right stimulus and motivation needs can be met.

\section{Recommendations}

(1) That the service of the hover doctor, who brings primary medical care to people in scattered communities along the Apurimac river should continue.

(2) That the group at most risk, mainly the children under 5 and their mothers, should remain the number one priority in the programme.

(3) That a full comprehensive vaccination programme, according to Peruvian government regulations, should be encouraged in the children under 5 .

(4) That each village community should be offered help, so long as that help is matched by help from the village community itself, in installing a safe and clean water supply.

(5) That a continuous teaching programme should be planned so that the sanitarios continue to learn. We believe that the seminar we arranged could be repeated two or three times each year. The part played by a schoolmaster in health care in villages where as yet there is no sanitario or clinic makes sense, for the schoolmaster is always an influential member of the village community. Change will come primarily through the younger members of a community.

(6) That efforts should be made to strengthen the base at San Francisco and develop the hospital there so that it can function as a referral centre for those patients that the sanitarios are unable to help.

(7) That only a basic number of medicines and supplies should be stocked and used in each clinic so that treatment and care can be simplified.

We have not concerned ourselves in this paper with the financial implications of running a service like this, for this was not our brief. Suffice it to say that small charges were made for consultations and medications. We believe that the clinics can and should be self supporting. The cost of running and maintaining the hovercraft may need funding either from government or a donor agency for several years in the same way that a mobile clinic is funded or an ambulance service is provided.

We acknowledge the help and advice given by the following: Dr D Morley, Institute of Tropical Child Health, London University, London; Colonel Holmes, Royal Army Medical College, Millbank, London; Miss V Collett, Community Health Dept, United Mission Hospital, Tansen, Nepal; Dr R Adley, RN Hospital, Devonport, Plymouth, and the late Dr A Reid who gave us valuable advice about the snakes of the region and the precautions we should take. Dr L J Hayek of Torbay Hospital gave us valuable help in the analysis of the village and river water samples.

What is the risk of acquiring silicosis from the dust of dry concrete?

Silicosis is caused by crystalline silica, primarily quartz, tridymite, and cristabolite. Concrete is composed of cement and an aggregate. Though some specialised types of cement may contain silica, the Portland and aluminous cements generally used in the construction industry are unlikely to contain any crystalline silica. The aggregate will, however, normally contain quartz in the form of sand. As a rule there will be no quartz particles below an aerodynamic diameter of $10 \mu \mathrm{m}$, which is the upper limit of the respirable-silicosis causing - range. ${ }^{1}$ (A particle of a given aerodynamic diameter is defined as one having the same settling speed and other aerodynamic properties as a unit density sphere of the same diameter. The geometric diameter can either be larger or smaller than the aerodynamic diameter.) Particles produced by the normal attrition processes from a concrete surface will not be further reduced in size so the risk, under the conditions described by the questioner, will be extremely small. Nevertheless, if the concrete is mechanically worked, such as by grinding to obtain a smooth surface, or is cut by a diamond saw, then undoubtedly particles below $10 \mu \mathrm{m}$ aerodynamic diameter will be produced. This may well lead to a risk of silicosis from prolonged or particularly heavy exposure to the dust produced. The appropriate exposure limit is $0.1 \mathrm{mg} / \mathrm{m}^{3}$ (eight hour time weighted average). ${ }^{2}$ The method of sampling adopted must be one that collects only the respirable portion of the dust.-F LUNAU, senior occupational hygienist, London.

'Parke WR. Occupational lung disorders. London: Butterworths, 1974. Health and Safety Executive. Threshold limit values. Guidance note HJ15. London:
Health and Safety Executive, 1980 . 